\title{
Measuring quantitative proteomic distance between Spanish beef breeds
}

R. Rodríguez-Vázquez ${ }^{\text {a }}$, A. Mato ${ }^{\text {a }}$, M. López-Pedrouso ${ }^{\text {a }}$ D. Franco ${ }^{\text {b }}$, M. A.

Sentandreu ${ }^{\mathrm{c}}$, C. Zapata ${ }^{\mathrm{a}, *}$

${ }^{a}$ Department of Zoology, Genetics and Physical Anthropology, University of Santiago de Compostela, 15782 Santiago de Compostela, Spain

${ }^{\mathrm{b}}$ Meat Technology Center of Galicia, 32900 San Cibrao das Viñas, Ourense, Spain

'Instituto de Agroquímica y Tecnología de Alimentos (CSIC), 46980 Paterna, Valencia, Spain

* Corresponding author at: Department of Zoology, Genetics and Physical Anthropology. University of Santiago de Compostela, 15782 Santiago de Compostela, Spain.
E-mail address: c.zapata@usc.es (C. Zapata). 


\section{Abstract}

Estimates of quantitative proteomic distance between populations have not been reported to date. Here, quantitative proteomic distances between three Spanish bovine breeds (Asturiana de los Valles, AV; Retinta, RE; and Rubia Gallega, RG) were estimated from two-dimensional electrophoresis profiles of meat samples of longissimus thoracis muscle at $2 \mathrm{~h}$ post-mortem. Statistically significant distances were detected between $\mathrm{AV} / \mathrm{RG}$ and the most genetically different $\mathrm{RE}$ breed, using the novel $Q D$ measure of quantitative proteomic distance. In total, 18 differentially abundant myofibrillar and sarcoplasmic proteins/isoforms contributing to proteomic distances between breeds were confidently identified by tandem mass spectrometry. The fast skeletal myosin regulatory light chain 2 followed by other five interacting proteins exhibited the most pronounced relative change between breeds. In addition, most differentially represented proteins could be associated with variations in meat tenderness. Therefore, they could be candidate biomarkers for molecular breeding programs and authentication of the three Spanish beef breeds.

Keywords: Meat proteomics, Population proteomics, Proteomic distance measures, QD measure, Beef tenderness biomarkers, Beef authenticity biomarkers 


\section{Introduction}

A total of 1019 local cattle breeds have been recorded in the Global Databank for Animal Genetic Resources (FAO, 2015). Crossbreeding programs spanning decades of research have shown far-reaching differences between cattle breeds for carcass composition (e.g. fat thickness and carcass weight) and meat quality (e.g. tenderness) characteristics that are variably influenced by genetic make-up and environmental factors (Burrow, Moore, Johnston, Barendse, \& Bindon, 2001). The application of highthroughput genomic technologies has provided valuable genome-wide data for thousands of markers, information about inter-breed genomic diversity and fueled the identification of quantitative trait loci (QTL) underlying inter-breed variations in carcass and beef quality attributes (Ramayo-Caldas, Renand, Ballester, Saintilan, \& Rocha, 2016; Medeiros de Oliveira Silva et al., 2017).

Comparative proteomics can provide extremely valuable superimposed information to genetic studies to unraveling the complex molecular pathways and candidate QTL involved in meat quality variations between cattle breeds (Ohsaki et al., 2007; Timperio, D’Alessandro, Pariset, D’Amici, \& Zolla, 2009; De Souza Rodrigues et al., 2017; Gagaoua, Terlouw, Richardson, Hocquette, \& Picard, 2019). First of all, proteomics enables the analysis of the final products of the expression of protein coding genes involved in muscle-to-meat conversion as well as exploring genotypeenvironment crosstalk establishing a bridge between the genotype and the phenotype. Second, differential protein abundance in comparative proteomics is an alternative approach to positional QTL cloning to discover the candidate protein QTL (pQTL) underlying the trait of interest (Acharjee et al., 2018). Comparative proteomics between breeds has the added advantage that facilitates pQTL identification because the differences for carcass and meat quality attributes are significantly larger than within- 
breed differences (Burrow et al., 2001). It also enables the discovery of breed-specific protein markers that can be used for meat authenticity and traceability throughout industrial production processes (Montowska \& Pospiech, 2012; Fontanesi, 2017). Proteomic distances can be a powerful tool for assessing summarized information on the degree of global proteomic divergence between populations. It must be highlighted, however, that the measurement of the proteomic distance is considerably more complex than the measurement of the genetic distance. In particular, the proteomic distance between a given pair of populations can undergo significant variations due to the enormous spatio-temporal plasticity of the proteome. To date, only a few studies have used proteomic distance measurements to assess the relationship of proteomic differentiation between populations with intraspecific phylogenetic diversity established by genetic markers in the parasite Trypanosoma cruzi (Telleria et al., 2010), genetic proximities between species and genus of the plant family Brassicaceae (Marquès, Sarazin, Chané-Favre, Zivy, \& Thiellment, 2001), variations in quality traits in the common bean (Phaseolus vulgaris) and potato (Solanum tuberosum) (López Pedrouso, Bernal, Franco, \& Zapata, 2014; Mouzo, López-Pedrouso, Bernal, García, Franco, \& Zapata, 2018), and changes in beef tenderness (Gagaoua et al., 2019). Proteomic distances were assessed using Jaccard's and Nei and Li's distance measures (Jaccard, 1908; Nei \& Li, 1979). These are proteomic distance measures of qualitative type, computed from the number of common and uncommon proteins between populations. Therefore, qualitative distances are useful when differences between proteomic profiles are qualitatively pronounced, exhibiting a large number of shared and unshared proteins. However, a more efficient and general measure of proteomic distance should also include quantitative differences in protein abundance. Measurements of distance computed from quantitative proteomic data have been traditionally used to assess the 
level of similarity/dissimilarity between populations by multivariate statistical methods such as the principal component and cluster analyses. To the best of our knowledge, however, no estimates of the quantitative distance summarizing in a single numerical value the degree of proteomic divergence between populations have been reported to date.

In this study, quantitative proteomic distances between $\mathrm{AV}, \mathrm{RE}$ and $\mathrm{RG}$ bovine breeds were assessed from two-dimensional electrophoresis (2-DE) proteomic profiles of longissimus thoracis (LT) muscle meats. These are the three major cattle breeds in the Spanish meat industry, accounting for ca. $78 \%$ of Spain's total beef production (MAPAMA, 2018). Proteomic distances between breed pairs were estimated by means of the recently proposed $Q D$ statistic that takes into account quantitative differential abundance of both shared and unshared proteins between populations (RodríguezVázquez \& Zapata, 2019). In addition, proteins contributing to proteomic distance between breeds were identified by MS/MS to gain deeper insights into the biochemical processes underlying distinctive meat characteristics and identify candidate protein markers for the authentication of the three Spanish beef breeds.

\section{Materials and methods}

\subsection{Bovine breeds and meat samples}

Three different bovine (Bos taurus L.) breeds raised in different Spanish regions were used in this study: AV (Asturias), RE (Extremadura) and RG (Galicia). Animals were transported from farms to accredited abattoirs and slaughtered following the requirements established by European Union legislation (Council Directive 93/119/EEC). Male calves of the three breeds were slaughtered at the usual age in the Spanish beef industry: 9-10 months in the AV and RE breeds and 5-6 months in the RG cattle breed. Meat samples from each cattle breed were collected at $2 \mathrm{~h}$ post-mortem to 
124 avoid proteomic differences caused by post-mortem meat processing variations among

125 slaughterhouses. One steak of $2 \mathrm{~cm}$ was excised from each animal at the thirteenth rib 126 position of the LT muscle. Meat samples were vacuum packed, transported to the 127 laboratory under refrigerated conditions, lyophilized and stored at $-80{ }^{\circ} \mathrm{C}$. Six 128 independent biological replicates of each of the three breeds were used for proteomic 129 analyses.

\subsection{Protein extraction and quantification}

Total protein was extracted from lyophilized meat samples as described by Franco et al. (2015). An amount of $50 \mathrm{mg}$ of each lyophilized sample was mixed with $1.5 \mathrm{~mL}$ of lysis buffer (7 $\mathrm{M}$ urea; $2 \mathrm{M}$ thiourea; $10 \mathrm{mM}$ dithiothreitol, DTT; 4\% CHAPS; and 2\% Pharmalyte ${ }^{\mathrm{TM}} \mathrm{pH} 3-10$, GE Healthcare, Chicago) and subjected to sonication (Sonifier 250, Branson, Danbury) in an ice-water bath. The proteins were purified using the Clean-Up Kit (GE Healthcare) and resuspended in $500 \mu \mathrm{L}$ of lysis buffer. Quantitation of the total protein concentration was performed with the CB-X protein assay kit (G-Biosciences, St. Louis) based on an improved Bradford method, using a Chromate 4300 (Awareness Technology, Palm City) microplate reader. Bovine serum albumin (BSA) was used as protein standard for calibration.

\subsection{Two-Dimensional Electrophoresis}

LT muscle proteins were separated by previously established 2-DE protocols (Franco et al., 2015). Briefly, $450 \mu \mathrm{g}$ of total protein extract were dissolved in lysis and rehydration (7 M urea, $2 \mathrm{M}$ thiourea, 4\% CHAPS, 0,002\% bromophenol) buffers along with $0.6 \%$ DTT and 1\% immobilized pH gradient (IPG) buffer (Bio-Rad Laboratories, Hercules). The mixture was loaded onto 24-cm-long IPG strips with linear $\mathrm{pH}$ gradient of 4-7 (Bio-Rad Laboratories). First dimensional isoelectric focusing (IEF) was performed using a PROTEAN IEF cell system (Bio-Rad Laboratories) applying an 
149 increasing voltage until reaching $70 \mathrm{kVh}$ after an initial rehydration step (50 V for 12

150 h). Focused strips were equilibrated with equilibration buffers I (50 mM Tris pH 8.8; 6

151 M urea; $1 \%$ DTT; 30\% glycerol; and 2\% sodium dodecyl sulphate, SDS) and II (50 mM

152 Tris $\mathrm{pH} 8.8,6 \mathrm{M}$ urea, 30\% glycerol; 2\% SDS; and 2.5\% iodoacetamide) for 15 min

153 each at room temperature. SDS-polyacrilamide gel electrophoresis (SDS-PAGE) for the

154 second dimension was performed by transferring strips to $13 \%(\mathrm{w} / \mathrm{v})$ gels of $24 \times 20 \mathrm{~cm}$

155 and run on an Ettan DALTsix vertical multigel electrophoresis system (GE, Healthcare)

156 at $18 \mathrm{~mA} / \mathrm{gel}$ for $15 \mathrm{~h}$ after an initial step of $6 \mathrm{~mA} / \mathrm{gel}$ for $1 \mathrm{~h}$. Gels were subsequently

157 stained with SYPRO Ruby fluorescent stain (Lonza, Rockland) following the

158 manufacturer's indications. Protein molecular mass markers between 15 to $200 \mathrm{kDa}$

159 (Fermentas, Ontario) were loaded into a lateral well of SDS-PAGE gels.

$160 \quad$ 2.4. Image analysis

The 2-DE gels were scanned using a Gel Doc XR + system (Bio-Rad

performed with PDQuest Advanced software v. 8.0.1 (Bio-Rad Laboratories) and manually checked. Normalized volumes of the spots were obtained after background subtraction using the total density of validated spots across all replicate gels. Only spots reproducibly validated in at least four replicates of each cattle breed were considered for further analyses. The isoelectric point $(\mathrm{p} I)$ and molecular weight $\left(M_{\mathrm{r}}\right)$ of each spot were obtained using as a reference the above-mentioned linear IPG strips $(\mathrm{pH} 4-7)$ and standard molecular mass markers, respectively.

\subsection{Protein identification by mass spectrometry}

Protein identification was accomplished by MALDI-TOF and MALDITOF/TOF MS as previously (Franco et al., 2015). Briefly, spots of interest were excised from gels and submitted to in-gel trypsin digestion. Eluted peptides were concentrated 
174 in a SpeedVac (Thermo Fisher Scientific, Waltham) and stored at $-20{ }^{\circ} \mathrm{C}$ until mass 175 spectrometric analysis. A mixture of peptides redissolved in formic acid and matrix solution was transferred onto a 384 well Opti-TOF MALDI target plate (Applied Biosystems, Foster City) using the thin layer method. Mass spectra were then recorded on a 4800 MALDI-TOF/TOF mass spectrometer (Applied Biosystems) in the positiveion reflector mode, an Nd:YAG laser with wavelength of $355 \mathrm{~nm}$ and an average of 1000 laser shots/spectrum. Mass calibration was performed using at least three trypsin autolysis peaks. Precursor ions for subsequent MS/MS fragment analysis were selected with a relative resolution of 300 full width at half-maximum (FWHM) and metastable suppression. The 4000 Series Explorer Software v. 3.5 (Applied Biosystems) was used to create an automated analyses of mass data. Search of peptide mass fingerprinting (PMF) and MSMS fragment-ion spectra data against the $B$. taurus UniProtKB/SwissProt non-redundant protein database was carried out through the GPS Explorer Software v. 3.6 using Mascot software v. 2.1 (Matrix Science, Boston), taking into account the following settings: a precursor and fragment ion mass tolerance of 30 ppm and $0.35 \mathrm{Da}$, respectively; the carbamidomethyl-Cys (CAM) and the oxidized methionine as fixed and variable modifications, respectively; and one missed cleavage allowed. Identifications by Mascot were manually validated. Protein identifications required at least three peptide matches to the same protein and Mascot's $P$-value $<0.05$ significance threshold.

\subsection{Statistical analysis}

Non-parametric bootstrap was used to obtain confidence intervals (CIs) for the means of spot volumes across replicates of each breed according to Franco et al. (2015). For each spot, 20000 bootstrap samples of size $n$ (number of replicates $=6$ ) were drawn 
constructed from a distribution of 20000 mean replications by the bias-corrected percentile method (Efron, 1982). Bootstrap CIs were corrected for multiple comparisons with the Bonferroni method to make the familywide error rate $\alpha$ equal to 0.05 . CIs were calculated using open-source R statistical software.

Quantitative changes of spot volumes between pairs of breeds were assessed by the fold change $(F C)$ and relative change $(R C)$ measures (Franco et al., 2015). The measure $F C$ between pairs of breeds was calculated by $F C_{\mathrm{AV}-\mathrm{RE}}=\mathrm{V}_{\mathrm{RE}} / \mathrm{V}_{\mathrm{AV}}, F C_{\mathrm{AV}-\mathrm{RG}}=$ $\mathrm{V}_{\mathrm{RG}} / \mathrm{V}_{\mathrm{AV}}, F C_{\mathrm{RE}-\mathrm{RG}}=\mathrm{V}_{\mathrm{RG}} / \mathrm{V}_{\mathrm{RE}}$, where $\mathrm{V}_{\mathrm{AV}}, \mathrm{V}_{\mathrm{RE}}$ and $\mathrm{V}_{\mathrm{RG}}$ are the mean volumes of the same spot on 2-DE gels from six replicate samples of the AV, RE and RG breeds, respectively. $F C$-values less than one were represented by their reciprocals with a negative sign. Therefore, $F C$ ranges from $-\infty$ to $+\infty$. The $R C$ measure is given by $R C=$ $\mathrm{DV} /|\mathrm{DV} \max |$ where $\mathrm{DV}$ is the differential volume of a given spot between pairs of breeds: $\mathrm{DV}_{\mathrm{AV}-\mathrm{RE}}=\mathrm{V}_{\mathrm{RE}}-\mathrm{V}_{\mathrm{AV}}, \mathrm{DV}_{\mathrm{AV}-\mathrm{RG}}=\mathrm{V}_{\mathrm{RG}}-\mathrm{V}_{\mathrm{AV}}$ and $\mathrm{DV} \mathrm{V}_{\mathrm{RE}-\mathrm{RG}}=\mathrm{V}_{\mathrm{RG}}-\mathrm{V}_{\mathrm{RE}}$; and where $\mathrm{DV}_{\max }$ is the maximum observed value of $\mathrm{DV}$ (in absolute value) across all pairwise comparisons. The range of $R C$ varies between -1.0 and +1.0 .

The relationship between samples from standardized spot volume data (mean of 0 and standard deviation of 1) was assessed with a principal component analysis (PCA) and the generation of the heatmap using XLSTAT software (v. 2014.5.03; Addinsoft, Andernach). An UPGMA (Unweighted Pair Group with Arithmetic Mean) dendrogram was generated to cluster the proteins with significant differential $(P<0.05)$ abundance between breeds from the matrix of $R C$-values in absolute value using XLSTAT software. Descriptive statistics were calculated using IBM SPSS Statistics software (v.24; SPSS, Chicago).

\subsection{Proteomic distance measures}


Qualitative proteomic distances between pairs of breeds were estimated using

224 Nei and Li's and Jaccard's distance indexes (Nei et al., 1979; Jaccard, 1908). Nei and

Li's dissimilarity index is given by $D=1-F$; where $F=2 n_{x y} /\left(n_{x}+n_{y}\right), n_{x y}$ is the total

number of spots shared between bovine breeds $x$ and $y$, and where $n_{x}$ and $n_{y}$ are the total

number of spots in breeds $x$ and $y$, respectively. Jaccard's dissimilarity index becomes $D$

$=1-J$, where $J=n_{x y} /\left(n_{x y}+a+b\right)$, and where $a$ and $b$ are unique spots only

represented in breeds $x$ and $y$, respectively. Quantitative changes in protein abundance between each pair of breeds were assessed using the $Q D$ measure of proteomic distance (Rodríguez-Vázquez et al., 2019), given by

$$
Q D=\left(\sum_{i=1}^{N}\left|R C_{i}\right| / N\right) p
$$

where $R C_{i}$ are the values of $R C$ across $N$ spots with statistically significant differential abundance between each pair of breeds and where $p$ is the proportion of significantly changing spots. Therefore, $Q D$ ranges from 0 to 1.0. Non-parametric bootstrap was used to construct $95 \%$ CIs for qualitative and quantitative proteomic distance measures by the bias-corrected percentile method adjusted with the Bonferroni method from 20000 bootstrap resamples.

\subsection{Bioinformatic analysis}

Functional categorization of differentially abundant proteins between breeds in the three different ontologies (i.e. biological process, cellular component and molecular function of gene products) was performed from high levels of Gene Ontology (GO) slim terms using the Slimmer tool of AmiGO software (Carbon et al., 2009). The QuickGO web-based tool (Binns, Dimmer, Huntley, Barrell, O’Donovan, \& Apweiler, 2009) was used for fine-grained information about each significantly changing protein between breeds. GO term enrichment analysis and over-representation of GO terms against the rest of the genome of B. taurus in KEGG and Interpro databases was performed with 
the FatiGO/Babelomics software (Alonso et al., 2015). Significant over-representation of GO terms was tested by means of the two-tailed Fisher exact test and global cut-off value for multiple testing was established by the false discovery rate (FDR) procedure.

The search for known and predicted networks of direct protein-protein interactions between differentially abundant proteins between breeds and interacting partners in the proteome of B. taurus was carried out using the STRING v11.0 proteinprotein interaction database (Szklarczyk et al., 2019).

\section{Results}

\subsection{Comparison of 2-DE profiles between bovine breeds}

Representative 2-DE protein profiles for LT meat samples of each Spanish bovine breed (AV, RE and $\mathrm{RG}$ ) are shown in Fig. 1. The detection, matching and volume measurement of 2-DE gel spots throughout six biological replicates of each breed was carried out using the PDQuest software. A total of 140 individual protein spots were matched across replicated gels of the three breeds. Mean volumes $( \pm$ SE, standard error) with their $95 \%$ bootstrap CIs for significantly changing protein spots between pairs of breeds are shown in Supplementary Table 1. These spots were numbered and marked on 2-DE gels (Fig. 1). Overall, 26.4\% (37 out of 140) of spots exhibited significant differential abundance between one or more pairs of breeds. A Venn diagram was generated to show the number of these 37 differentially represented protein spots that are shared and unshared by the three breeds (Supplementary Fig. 1). A total of $17(45.9 \%)$ and 1-5 (2.7-13.5\%) spots coincided among the three breeds and between pairs of breeds, respectively. Five unshared or unique spots were detected in both AV (spots 5, 19, 20, 28 and 35) and RE (spots 4, 6, 14, 24 and 26), while unique spots were no identified in the RG breed. 
The principal component analysis (PCA) ordination method and heat map clustering were used to obtain summarized information about the relationships between the 37 protein spots with significant differential $(P<0.05)$ abundance between breeds.

The two-dimensional PCA-plot shows that the first two principal components account for over $63 \%$ of the total variation in the data (Supplementary Fig. 2). The first principal component ( $41 \%$ of the total variation) clearly differentiated the samples into three well-separated clusters that correspond to the three breeds. The heat map showed that samples are divided into the same three clusters (left dendrogram, Fig. 2). The most separated cluster corresponds to RE meat samples, while clusters of AV and RG samples were closer to each other. These results indicate that 2-DE proteome profiles allowed the successfully allocation of each meat sample to the breed of origin.

\subsection{Identification of differentially changing proteins}

In total, 25 out of 37 differentially abundant protein spots between pairs of breeds were confidently $(P<0.05)$ identified by MALDI-TOF and MALDI-TOF/TOF MS (Table 1). The comparison between the theoretical (Th) and observed (Obs) $M_{\mathrm{r}}$ of each protein was used to exclude degraded proteins from further analysis. We considered that proteins were degraded when the ratio $M_{\mathrm{r}}(\mathrm{Th}) / M_{\mathrm{r}}(\mathrm{Obs})>1.5$, as previously (López-Pedrouso et al., 2018). A total of 7 proteins identified fulfil this criterion: EOGT (spot 14); FAM110A (spot 32); DUSP11 (spot 33); FAM110A-1 (spot 34); ATXN10 (spot 35); BCAT2 (spot 36); and SCKA1 (spot 37). Consequently, 18 protein spots and 12 non-redundant proteins differentially represented in bovine meat samples were eventually selected and used hereafter in further analyses: MYBPH (spot 1), MYBPH-1 (spot 3), CKM (spot 9), PRDX3 (spot 11), PRDX3-1 (spot 26), ACTA1 (spot 12), ACTA1-1 (spot 18), PDHB (spot 13), PDHB-1 (spot 16), TNNT1 (spot 17), 
ANK2 (spot 19), YWHAE (spot 21), CCNG1 (spot 22), MYL6B (spot 25), TMEM233 (spot 27), MYLPF (spot 29), MYLPF-1 (spot 30) and MYLPF-2 (spot 31 ).

\subsection{Quantitation of the extent of change in protein abundance between breeds} provides a more efficient overall estimation of the extent of change in protein abundance between breeds than the traditionally used $F C$ measure. The $F C$ measure gives values of $-\infty$ or $+\infty$ for unshared or unique protein spots regardless of the differences in volume between breeds. In contrast, $R C$ is a measure that ranges from 1.0 to +1.0 and quantifies the existing differential abundance across both shared and unshared proteins (Franco et al., 2015; López-Pedrouso et al., 2018; Mato, Rodríguez-

Vázquez, López-Pedrouso, Bravo, Franco, \& Zapata, 2019). Note that $R C$-estimates (in absolute value) across pairwise comparisons with $F C$-values of $-\infty$ or $+\infty$ in the present study ranged from 0.008 to 0.081 and averaged $( \pm \mathrm{SE}) 0.023 \pm 0.004$ (Supplementary Table 2).

Estimates of $R C$ between breeds disclosed several outstanding facts. First, changes in protein abundance were higher in pairwise comparisons including the RE breed. Thus, the mean ( $\pm \mathrm{SE}$ ) of $R C$-values between AV-RE and RE-RG breeds was $0.169 \pm 0.099$ and $0.175 \pm 0.088$, respectively, whereas for AV-RG breeds the mean decreased remarkably to $0.026 \pm 0.006$. These differences in $R C$ mean values were statistically significant using $95 \%$ bootstrap CIs obtained by the bias-corrected

317 percentile method. Secondly, MYLPF and MYLPF-2 were the proteins with the most pronounced differential abundance between AV-RE $(R C=+1.0)$ and RE-RG breeds $(R C=+0.495)$, respectively, whereas between AV-RG breeds was the CKM protein 
321 MYLPF/MYLPF-2, MYLPF and CKM proteins formed separated subclusters in

$322 \mathrm{AV} / \mathrm{RE}, \mathrm{RE} / \mathrm{RG}$ and $\mathrm{AV} / \mathrm{RG}$ dendrograms, respectively, constructed from the matrix of 323 pairwise differences between $R C$ s in absolute value (Fig. 3).

3.4. Bioinformatic analysis of identified proteins

The map of granular annotations and fine-grained information for the 12 differentially $(P<0.05)$ abundant proteins between breeds from GO terms retrieved through AmiGO and QuickGO tools are shown in Supplementary Fig. 3 and Supplementary Table 3, respectively. Proteins were involved in three ontology categories: i) cellular component (e.g. nucleus, cytoskeleton, extracellular space and myosin and troponin complexes); ii) molecular function (e.g. calcium ion binding, apoptotic process and catalytic activity); and iii) biological process (e. g. regulation of cell cycle, sarcomere organization and skeletal muscle development and assembly). No statistically significant over-representation of GO terms against the rest of the genome of B. taurus was detected from KEGG and Interpro databases following term enrichment analysis with the FatiGO/Babelomics software. $\mathrm{AV}, \mathrm{RE}$ and RG breeds according to the STRING database is shown in Fig. 4. The resulting STRING map disclosed a single protein-protein interaction network that includes 6 out of 12 changing proteins. Interacting proteins are myofibrillar proteins involved in muscle structure-contraction (MYLPF, MYL6B, MYBPH, ACTA1),

341 regulation of muscle contraction (TNNT1) and energy metabolism (CKM). It is 342 noteworthy that MYLPF is the only node interacting with the rest of proteins of the interaction network. 
Qualitative and quantitative proteomic distances between pairs of breeds are shown in Fig. 5 and Supplementary Table 4. Qualitative distances estimated by Nei and

347 Li's $D$ measure were lower that those distances estimated by Jaccard's $D$ measure. It can be mathematically proven that both measurements report the same distance value only if all spots are either shared $\left(n_{x y}=1 ; D=0\right)$ or unshared $\left(n_{x y}=0, D=1\right)$; otherwise $\left(n_{x y} \neq 1\right.$ and 0$)$, Nei and Li's $D$ scores are always lower than those of Jaccard's $D$ measure. Overall, qualitative distances between AV-RE and RE-RG breeds were slightly higher than between AV-RG breeds, but not statistically different from each other. In contrast, statistically significant proteomic differentiation between breed pairs was detected by using the $Q D$ measure of quantitative proteomic distance (Fig. 5 and

Supplementary Table 4). More specifically, quantitative distances were very similar between AV-RE $(Q D=0.0145)$ and RE-RG $(Q D=0.0142)$ breeds $(P>0.05)$, but about ten times higher than between AV-RG $(Q D=0.0014)$ breeds $(P<0.05)$.

\section{Discussion}

Estimates of qualitative and quantitative proteomic distances calculated from 2-

DE profiles of meat samples from LT muscle provided opposite information about the overall proteomic differentiation between Spanish bovine breeds. Proteomic distance between breeds was statistically validated only from quantitative differences in protein abundance. For this purpose, we used the $Q D$ measure specifically tailored to estimate distances between populations from quantitative proteomic data. Several lines of evidence support the satisfactory behavior of the $Q D$ statistic for measuring quantitative distances between populations. First of all, our observations indicate that the overall proteomic profiles of $\mathrm{AV}$ and $\mathrm{RG}$ meats were noticeably differentiated $\left(Q D_{\mathrm{AV}-\mathrm{RG}}=\right.$ $0.0014)$ from RE meat $\left(Q D_{\mathrm{AV}-\mathrm{RE}}=0.0145 ; Q D_{\mathrm{RE}-\mathrm{RG}}=0.0142 ; P<0.05\right)$. There results are consistent with the heat map clustering analysis based on differentially $(P<0.05)$ 
370

371

372

represented proteins, showing that AV y RG breeds are grouped into two close subclusters clearly separated from the RE breed. Likewise, the hierarchical neighbourjoining (NJ) tree for 40 Iberian Peninsula cattle breeds using kinship distances computed from microsatellite marker data showed that AV is more closely related to RG than to RE (Cañón et al., 2011). This latter result is in agreement with genetic distance estimates between the three Spanish cattle breeds using the bovine high-density single-nucleotide polymorphism (SNP) chip (Cañas-Álvarez et al., 2015). More specifically, reported values of Nei's $D$ genetic distance were lower between AV-RG breeds $(D=0.0095)$ than between RE and both AV and RG breeds $(D=0.0109$ $0.0137)$.

A total of 18 differentially abundant 2-DE protein spots containing 12 nonredundant myofibrillar and sarcoplasmic proteins, with a variable number of isoforms (zero to three), contributed to explaining proteomic distances between Spanish breeds. Proteins identified are involved in structural-contractile (MYBPH, ACTA1, ANK2, TNNT1, MYL6B and MYLPF), metabolism (CKM, PRDX3, PDHB and YWHAE), regulation of cell cycle (CCNG1) and nervous system development (TMEM233) related functions. Some of them might be candidate proteins involved in the existing differences between the three breeds for meat tenderness. Meat tenderness from the LT muscle of male calves of the three breeds was previously evaluated using the WarnerBratzler shear force (WBSF) test (López-Pedrouso et al., 2019). The results of the WBSF test revealed statistically significant differences $(P<0.001)$ in tenderness between all pairs of sample groups. More specifically, RE and RG beefs were the least and most tender, respectively, while that of AV took intermediate tenderness scores.

MYLPF and interacting proteins can play a key role in causing differences in tenderness between the three Spanish cattle breeds. Thus, isoforms of MYLPF (i.e. 
MYLPF, MYLPF-1 and MYLPF-2) were the proteins with the most pronounced relative change in protein abundance between $\mathrm{RE}$ and AV/RG meats (absolute values of $R C$ ranged from 0.30 to 1.0 ). In contrast, no differential abundance of MYLPF isoforms was detected between AV and RG meats. MYLPF is a phosphoprotein with levels of phosphorylation modulated by the concerted action of $\mathrm{Ca} 2+/$ calmodulin-dependent skeletal muscle myosin light chain kinase and protein phosphatase type 1 activities (Stull, Kamm, \& Vandenboom, 2011). A number of studies in bovine, ovine and porcine have shown that changes in MYLPF phosphorylation levels are related to phenomena with impact in meat tenderness such as the skeletal muscle contraction force of fast-twitch fibers type IIb, the progress of rigor mortis, the response to pre-slaughter stress, actomyosin dissociation and myosin degradation (Muroya, Ohnishi-Kameyama, Oe, Nakajima, Shibata, \& Chikuni, 2007; Franco et al., 2015; Chen et al., 2016; Lana \& Zolla, 2016; Cao, Hou, Shen, Zhang, \& Wang, 2019; Mato et al., 2019). In addition, we found that MYLPF is the single protein interacting with all partners (i.e. MYBPH, ACTA1; MYL6B, TNNT1 and CKM) of the protein-protein interaction network identified in our study. Changes in abundance/phosphorylation of all these interacting proteins have been consistently related to meat tenderness variations (Franco et al., 2015; Lana et al., 2016; Mato et al., 2019; Picard \& Gagaoua, 2010). Differential abundance/phosphorylation of MYLPF (or other MYL2 isoforms), MYBPH, TNNT1, and CKM, between meat samples of longissimus muscle from different cattle breeds (Japanese Black vs. Holstein; Angus vs. Nellore; and Blond d'Aquitaine vs. Charolais and Limousin) have been previously reported (Ohsaki et al., 2007; Chaze et al., 2013; 417 de Souza Rodrigues et al., 2017). Overall, our study suggests that MYLPF isoforms and 418 the network of interacting proteins constitute the main candidate markers of beef 419 tenderness variations in the three Spanish bovine breeds. 
Another subset of differentially abundant proteins in the three Spanish breeds

421

422

423

424

425

426

427

428

429

430

431

432

433

434

(i.e. ANK2, PRDX3, PDHB, YWHAE, CCNG1 and TMEM233) did not show proteinprotein interactions according to STRING database. Several of these proteins have been related to a number of beef quality traits, including tenderness and water holding capacity. Thus, ANK2 is a member of a family of structural proteins linking the integral membrane proteins to the underlying spectrin-actin cytoskeleton in a complex network of inter-myofibril and myofibril-sarcolemma connections that can be degraded by calpains, thus leading to meat tenderization (Aslan, Sweeney, Mullen, \& Hamill, 2010). Polymorphisms in the bovine ANK1 have been associated with tenderness and intramuscular fat content, while in pork have bean associated with shear force, waterbinding capacity, drip loss and other parameters related to meat-quality traits (Wimmers et al., 2007; Aslan et al., 2010). In accordance with this evidence, the ANK2 protein was identified only in more tender meat from AV and RG breeds. The PRDX 3 belongs to a ubiquitous family of cysteine-based peroxidases with a protective antioxidant function (Perkins, Nelson, Parsonage, Poole, \& Karplus, 2015). Another peroxiredoxin, PRDX6, is considered to be a good marker of beef tenderness due to its anti-apoptotic properties (Gagaoua et al., 2019). The precursor protein of PRDX3 was recently associated with tender meat samples in Norwegian Red cattle (Grabĕz et al., 2015). Interestingly, we also found that the PRDX3 precursor protein (spot 11) was only identified in more tender meat of the AV and RG breeds. However, the active form of PRDX3 (PRDX3-1, spot 26) was only identified in less tender meat of RE cattle, the same negative relationship with tenderization that the PRDX6 peroxiredoxin. Finally, YWHAE belongs to the 14-3-3 protein family that binds to functionally diverse signaling proteins (Fu, Subramanian, \& Masters, 2000). It was proposed that YWHAE phosphorylation might be involved in beef tenderness by preventing apoptosis and 
445 increasing muscle contraction force (de Souza Rodrigues et al., 2017). However,

446 YWHAE was only identified in more tender meat of AV and RG breeds, which

447 suggests that it might be the unphosphorylated isoform of the protein.

448 The detection of breed-specific protein markers is useful for the authentication

449 of the origin of the meat to guarantee food quality and safety (Fontanesi, 2017). PCA

450 and heat map analyses disclosed that individual meats of each of the three Spanish

451 breeds can be distinguished unambiguously from global 2-DE proteome profiles. Single

452 proteins with changes in abundance between the three breeds could also be used for

453 meat authenticity. In particular, MYLPF isoforms would be good candidate markers for

454 this purpose because they underwent the most pronounced quantitative change between

455 breeds. It has been reported that the combination of different isoforms of the myosin

456 light chain enables differentiation between beef, pork and poultry due to the low 457 susceptibility of these isoforms to proteolytic degradation (Sentandreu, Fraser, Halket, 458 Patel, \& Bramley, 2010; Montowska \& Pospiech, 2012). Further follow-up research is 459 needed to establish whether these protein markers can be applied for beef authentication 460 and traceability in a wider range of scenarios, including different breeds, muscles and 461 beef aging.

\section{Conclusions}

This study leads us to conclude that the measurement of quantitative proteomic distance is a valuable approach for the assessment of the degree of overall divergence of 465 the functional genome between populations, the sub-proteome linked to their variations 466 in biological traits and protein markers of populations. Comparative analysis between qualitative and quantitative distance measures also showed that quantitative distances provide more reliable information on the extent of proteomic differentiation between populations. Overall, our results suggest new avenues for research and practical 
470 applications in population proteomics, including the assessment of the relative

471 efficiency of gel-based and gel-free driven proteomic studies in the estimation of 472 proteomic distance, spatio-temporal variations in proteomic distance and the 473 relationship between proteomic distance and the differentiation underlying biological 474 traits.

\section{Declaration of Competing Interest}

476 The authors declare that they have no known competing financial interests or 477 personal relationships that could have appeared to influence the work reported in this 478 paper.

\section{Acknowledgments}

480 This work was supported by the Instituto Nacional de Investigación y 481 Tecnología Agraria (INIA, RTA 2014-00034-C04), Spain; and by a predoctoral 482 fellowship of the Xunta de Galicia (Spain) and the European Union (ESF) to R. 483 Rodríguez-Vázquez.

\section{Appendix A. Supplementary data}


487

\section{References}

Acharjee, A., Chibon, P.-Y., Kloosterman, B., America, T., Renault, J., Maliepaard, C., \& Visser, R. G. F. (2018). Genetic genomics of quality related traits in potato tubers using proteomics. BMC Plant Biology, 18, 1-10.

Alonso, R., Salavert, F., Garcia-Garcia, F., Carbonell-Caballero, J., Bleda, M., GarciaAlonso, L., Sanchis-Juan, A., Perez-Gil, D., Marin-Garcia, P., Sanchez, R., Cubuk, C., Hidalgo, M. R., Amadoz, A., Hernansaiz-Ballesteros, R. D., Alemán, A., Tarraga, J., Montaner, D., Medina, I., \& Dopazo, J. (2015). Babelomics 5.0: functional interpretation for new generations of genomic data. Nucleic Acids Research, 43, W117-W121.

Aslan, O., Sweeney T., Mullen, A. M., \& Hamill, R. M. (2010). Regulatory polymorphisms in the bovine Ankyrin 1 gene promoter are associated with tenderness and intramuscular fat content. BMC Genetics, 11, 111.

Binns, D., Dimmer, E., Huntley, R., Barrell, D., O’Donovan, C., \& Apweiler, R. (2009). QuikGo: a web-based tool for Gene Ontology searching. Bioinformatics, 25, 30453046.

Burrow, H. M., Moore, S. S., Johnston, D. J., Barendse, W., \& Bindon, B. M. (2001). Quantitative and molecular genetic influences on properties of beef: a review. Australian Journal of Experimental Agriculture, 41, 893-919.

Cañas-Álvarez, J. J., González-Rodríguez, A., Munilla, S., Varona, L., Díaz, C., Baro, J. A., Altarriba, J., Molina, A., \& Piedrafita, J. (2015). Genetic diversity and divergence among Spanish beef cattle breeds assessed by a bovine high-density SNP chip. Journal of Animal Science, 93, 5164-5174.

Cañón, J., García, D., Delgado, J. V., Dunner, S., Da Gama, L. T., Landi, V., MartínBurriel, I., Martínez, A., Penedo, C., Rodellar, C., Zaragoza, P., \& Ginja, C. 
(2011). Relative breed contributions to neutral genetic diversity of a comprehensive representation of Iberian native cattle. Animal, 5, 1323-1334.

Cao, L., Hou, C., Shen, Q., Zhang, D., \& Wang, Z. (2019). Phosphorylation of myosin regulatory chain affects actomyosin dissociation and myosin degradation. International Journal of Food Science and Technology, 54, 2246-2255.

Carbon, S., Ireland, A., Mungall, C. J., Shu, S. Q., Marshall, B., Lewis S., the AmiGo Hub, \& the Web Presence Working Group. (2009). AmiGO: online access to ontology and annotation data. Bioinformatics, 2, 288-289.

Chaze, T., Hocquette, J.-F., Meunier, G., Renand, G., Jurie, C., Chambon, C., Journaux, L., Rousset, S., Denoyelle, C., Lepetit, J., \& Picard, B. (2013). Biological markers for meat tenderness of the three main French beef breeds using 2-DE and MS approach. In F. Toldrá, \& L. M. L. Nollet (Eds.), Proteomics in Foods: Principles and Application, Food Microbiology and Food Safety (pp. 127-146). New York: Springer Science+Business Media.

Chen, L., Li, X., Ni, N., Liu, Y., Chen, L., Wang, Z., Shen, Q. W., \& Zhang, D. (2016). Phosphorylation of myofibrillar proteins in post-mortem ovine muscle with different tenderness. Journal of the Science of Food and Agriculture, 96, 1474-83.

De Souza Rodrigues, R. T., Chizzotti, M. L., Vital, C. E., Baracat-Pereira, M. C., Barros, E., Busato K. C., Gomes, R. A., Ladeira, M. M., \& da Silva Martins, T. (2017). Differences in beef quality between Angus (Bos taurus taurus) and Nellore (Bos taurus indicus) cattle through a proteomic and phosphoproteomic approach. PloS One, 12 (1), e0170294.

Efron, B. (1982). The jacknife, the bootstrap and other resampling plans. Philadelphia: Society for Industrial and Applied Mathematics, (Chapter 10). 
FAO. The second report on the state of the world's animal genetic resources for food and agriculture. (2015). http://www.fao.org/3/a-i4787e.pdf. Accessed 13.11.2019.

Fontanesi, L. (2017). Meat authenticity and traceability. In F. Toldra (Ed), Lawrie's Meat Science (pp. 585-633). England: Woodhead Publishing.

Franco, D., Mato, A., Salgado, F. J., López-Pedrouso, M., Carrera, M., Bravo, S., Parrado, M., Gallardo, J., \& Zapata, C. (2015). Tackling proteome changes in the longissimus thoracis bovine muscle in response to pre-slaughter stress. Journal of Proteomics, 122, 73-85.

Fu, H., Subramanian, R. R., \& Masters, S. C. (2000). 14-3-3 proteins: structure, function and regulation. Annual Review of Pharmacology and Toxicology, 40, 617647.

Gagaoua, M., Terlouw, C., Richardson, I., Hocquette, J.-F., \& Picard, B. (2019). The associations between proteomic biomarkers and beef tenderness depend on the end-point cooking temperature, the country origin of the panelists and breed. Meat Science, 157, 107871.

Graběz, V., Kathri, M., Phung, V., Moe, K. M., Slinde, E., Skaugen, M., Saarem, K., \& Egelandsdal, B. (2015). Protein expression and oxygen consumption rate of early post-mortem mitochondria relate to meat tenderness. Journal of Animal Science, 93, 1967-1979.

Jaccard, P. (1908). Nouvelles recherches sur la distribution florale. Bulletin de la Société Vaudoise des Sciences Naturelles, 44, 223-270.

Lana, A., \& Zolla L. (2016). Proteolysis in meat tenderization from the point of view of each single protein: A proteomic perspective. Journal of Proteomics, 47, 85-97.

López-Pedrouso, M., Bernal, J., Franco, D., \& Zapata, C. (2014). Evaluating twodimensional electrophoresis profiles of the protein phaseolin as markers of genetic 
differentiation and seed protein quality in common bean (Phaseolus vulgaris L.). Journal of Agricultural and Food Chemistry, 62, 7200-7208.

López-Pedrouso, M., Pérez-Santaescolática, C., Franco, D., Fulladosa, E., Carvallo, J., Zapata, C., \& Lorenzo, J. M. (2018). Comparative proteomic profiling of myofibrillar proteins in dry-cured ham with different proteolysis indices and adhesiveness. Food Chemistry, 244, 238-245.

López-Pedrouso, M., Rodríguez-Vázquez, R., Purriños, L., Oliván, M., García-Torres, S., Sentandreu, M. A., Lorenzo, J. M., Zapata, C., \& Franco, D. (2019). Sensory analysis of three Spanish breeds in different livestock production systems and preslaughter handling conditions. Unpublished results.

MAPAMA. Datos de las Denominaciones de Origen Protegidas (D.O.P.), Indicaciones Geográficas Protegidas (I.G.P.) y Especialidades Tradicionales Garantizadas (E.T.G.) de Productos Agroalimentarios. Secretaría General de Agricultura y Alimentación. (2018). http://www.mapama.gob.es/es/alimentacion/temas/calidadagroalimentaria/informedop_igp_2016_ver4 tcm30-437834.pdf. Accessed 13-11$\underline{2019}$.

Marquès, K., Sarazin, B., Chané-Favre, L., Zivy, M., \& Thiellement, H. (2001). Comparative proteomics to establish genetic relationships in the Brassicaceae family. Proteomics, 1, 1457-1462.

Mato, A., Rodríguez-Vázquez, R., López-Pedrouso, M., Bravo, S., Franco, D., \& Zapata, C. (2019). The first evidence of global meat phosphoproteome changes in response to pre-slaughter stress. BMC Genomics, 20, 590.

Medeiros de Oliveira Silva, R., Bonvino Stafuzza, N., de Oliveira Fragomeni, B., Miguel Ferreira de Camargo, G., Matos Ceacero, T., Noely dos Santos Gonçalves Cyrillo, J., Baldi, F., Augusti Boligon, A., Zelotti Mercadante, M. E., Lino 
Lourenco, D., Misztal, I., Galvao de Albuquerque, L. (2017). Genome-wide association study for carcass traits in an experimental Nelore cattle population. PloS One, 12 (1), e0169860.

Montowska, M., \& Pospiech, E. (2012). Myosin light chain isoforms retain their species-specific electrophoretic mobility after processing, which enables differentiation between six species: 2DE analysis of minced meat and meat products made from beef, pork and poultry. Proteomics, 12, 2879-2889.

Mouzo, D., López-Pedrouso, M., Bernal, J., García, L., Franco, D., \& Zapata, C. (2018). Association of patatin-based proteomic distances with potato (Solanum tuberosum L.) quality traits. Journal of Agricultural and Food Chemistry, 66, 11864-11872.

Muroya, S., Ohnishi-Kameyama, M., Oe, M., Nakajima, I., Shibata, M., \& Chikuni, K. (2007). Double phosphorylation of the myosin regulatory light chain during rigor mortis of bovine longissimus muscle. Journal of Agriculture and Food Chemistry, $55,3998-4004$.

Nei, M., Li, W. H. (1979). Mathematical model for studying genetic variation in terms of restriction endonucleases. Proceedings of the National Academy of Sciences of the United States of America, 76, 5269-5273.

Ohsaki, H., Okada, M., Sasazaki, S., Hinenoya, T., Sawa, T., Iwanaga, S., Tsuruta, H., Mukai, F., \& Mannen, H. (2007). Proteomic comparison between Japanese Black and Holstein cattle by two-dimensional gel electrophoresis and identification of proteins. Asian-Australasian Journal of Animal Sciences, 20, 638-644.

Perkins, A., Nelson, K. J., Parsonage, D., Poole, L. B., \& Karplus, P. A. (2015). Peroxiredoxins: Guardians against oxidative stress and modulators of peroxide signaling. Trends in Biochemical. Sciences, 40, 435-445. 
610 Picard, B., \& Gagaoua, M. (2020). Meta-proteomics for the discovery of protein biomarkers of beef tenderness: An overview of integrated studies. Food Research International, 127, 108739.

Ramayo-Caldas, Y., Renand, G., Ballester, M., Saintilan, R., \& Rocha, D. (2016). Multi-breed and multi-trait co-association analysis of meat tenderness and other meat quality traits in three French cattle breeds. Genetics Selection Evolution, 48, 37.

617 Rodríguez-Vázquez, R., \& Zapata, C. (2019, September). A novel measure of quantitative proteomic distance. Poster session presentation at the 2nd Food Chemistry Conference, Sevilla, Spain.

Sentandreu, M. A., Fraser, P. D., Halket, J., Patel, R., \& Bramley, M. (2010). A proteomic-based approach for detection of chicken in meat mixes. Journal of Proteome Research, 9, 3374-3383.

Stull, J. T., Kamm, K. E., \& Vandenboom, R. (2011). Myosin light chain kinase and the role of myosin light chain phosphorylation in skeletal muscle. Archives of Biochemistry and Biophysics, 510, 120-128.

Szklarczyk, D., Gable, A. L., Lyon, D., Junge, A., Wyder, S., Huerta-Cepas, J., 627 Simonovic, M., Doncheva, N. T., Morris, J. H., Bork, P., Jensen, L. J., \& von Mering, C. (2019). STRING v11: protein-protein association networks with increased coverage, supporting functional discovery in genome-wide experimental datasets. Nucleic Acids Research, 47, D607-613.

Telleria, J., Biron, D. G., Brizard, J.-P., Demettre, E., Séveno, M., Barnabé, C., Ayala, F. J., \& Tibayrenc, M. (2010). Phylogenetic character mapping of proteomic diversity shows high correlation with subspecific phylogenetic diversity in 

United States of America, 107, 20411-20416.

636 Timperio, A. M., D'Alessandro, A.; Pariset, L., D'Amici, G. M., Valentini, A., \& Zolla, L. (2009). Comparative proteomics and transcriptomics analyses of livers from two different Bos taurus breeds: "Chianina and Holstein Friesian". Journal of Proteomics, 73, 309-322.

640 Wimmers, K., Murani, E., Te Pas, M. F. W., Chang, K. C., Davoli, R., Merks, J. W. M., 641 Henne, H., Muraniova, M., da Costa, N., Harlizius, B., Schellander, K., Böll, I., Braglia, S., de Witt, A. A. C., Cagnazzo, M., Fontanesi, L., Prins, D., \& Ponsuksili, S. (2007). Associations of functional candidate genes derived from gene-expression profiles of prenatal porcine muscle tissue with meat quality and muscle deposition. Animal Genetics, 38, 474-484.

646 
647 Figure captions

648 Fig. 1. Representative SYPRO Ruby-stained 2-DE gel images from LT meat samples of 649 different Spanish bovine breeds (AV, RE and RG). Differentially represented $(P<0.05)$ 650 protein spots between meat samples are marked and numbered.

651 Fig. 2. Heat map for normalized volume of protein spots with differential $(P$-value $<$ 652 0.05) abundance between $\mathrm{AV}, \mathrm{RE}$ and RG breeds. Green and red colors represent 653 relatively high and low values of protein abundance, respectively.

654 Fig. 3. UPGMA clustering dendrogram based on the matrix of pairwise differences in $655 R C$ (absolute values) of differentially $(P<0.05)$ changing proteins between AV-RG 656 (A), AV-RG (B) and RE-RG (C) bovine breeds.

657 Fig. 4. Protein-protein interaction network of differentially abundant proteins between $658 \mathrm{AV}, \mathrm{RE}$ and RG breeds, according to STRING confidence view (specific settings: 659 number of interaction to show, zero in the first and the second shell). The nodes 660 (circles) represent proteins and, the edges show known or predicted functional 661 associations (threshold: 0.4, medium confidence interval), and the colored lines indicate 662 the various types of interaction evidence (blue: co-occurrence; black: coexpression; 663 light blue: database evidence; green: neighborhood evidence; purple: experimental 664 evidence; red: fusion evidence; yellow: text mining evidence).

665 Fig. 5. Qualitative (Nei and Li's and Jaccard's $D$ ) and quantitative $(Q D)$ proteomic 666 distances between bovine breeds ( $\mathrm{AV}, \mathrm{RE}$ and $\mathrm{RG}$ ) from meats of LT muscle. 667 Statistically significant differences $(P<0.05)$ between estimates of proteomic distance 668 assessed by $95 \%$ bootstrap confidence intervals are indicated with different lower case 669 letters (a and b). 


\section{Table 1}

Differentially represented $(P<0.05)$ 2-DE protein spots between beef breeds $(\mathrm{AV}, \mathrm{RE}$ and RG) identified by MALDI-TOF and MALDI-TOF/TOF MS.

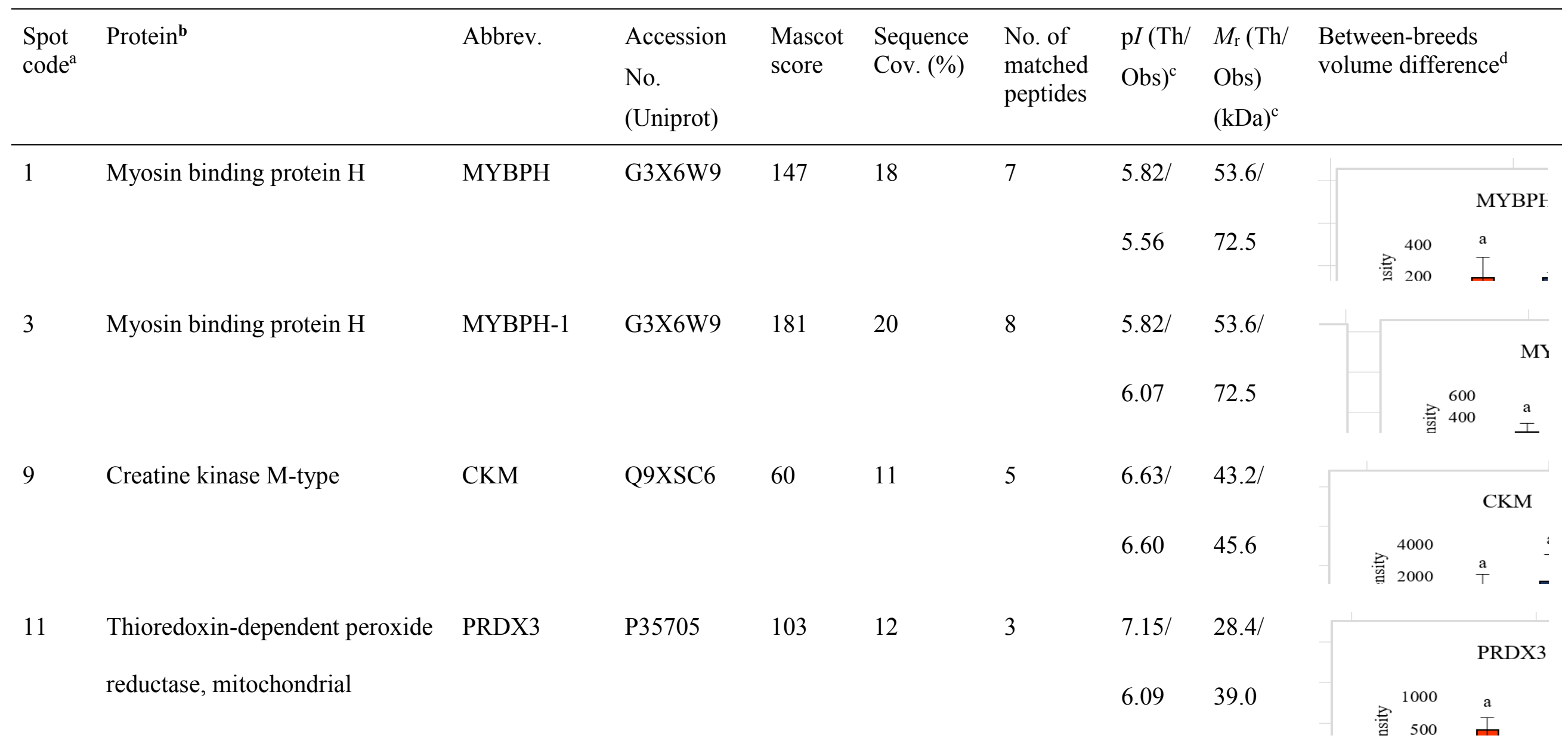


precursor

12

\section{Actin alpha 1 skeletal muscle}

\section{ACTA1}

P68138

83

12

P11966

67

43

component subunit beta,

mitochondrial

14 EGF domain-specific O-linked

EOGT

$\mathrm{N}$-acetylglucosamine transferase

A0JND3

51

11

8

10

PDHB-1

P11966

67

27

component subunit beta,

mitochondrial

\section{$6.87 / \quad 62.5 /$ \\ 6.11 \\ 39.0}
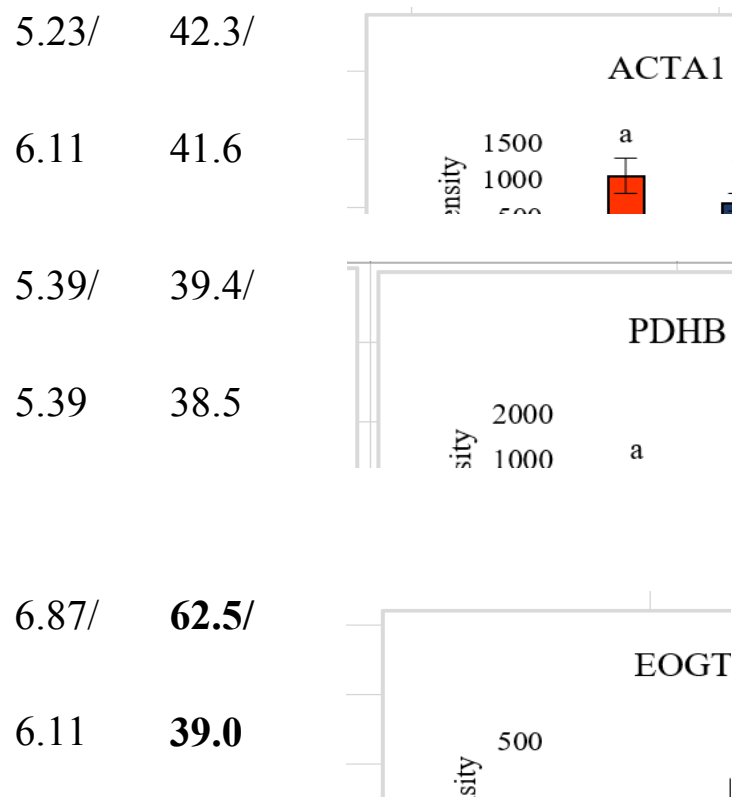

$\begin{array}{ll}6.21 / & 39.4 / \\ 5.44 & 38.0\end{array}$

PDHB

2000 


\begin{tabular}{|c|c|c|c|c|c|c|c|c|c|c|}
\hline \multirow[t]{2}{*}{17} & \multirow[t]{2}{*}{ Troponin T, slow skeletal muscle } & \multirow[t]{2}{*}{ TNNT1 } & \multirow[t]{2}{*}{ Q8MKH6 } & \multirow[t]{2}{*}{78} & \multirow[t]{2}{*}{7} & \multirow[t]{2}{*}{3} & $5.71 /$ & $31.3 /$ & \multicolumn{2}{|r|}{ TNNT1 } \\
\hline & & & & & & & 5.53 & 37.0 & $\Xi_{n n n}^{4000}$ & $\stackrel{\mathrm{a}}{-}$ \\
\hline \multirow[t]{2}{*}{18} & \multirow[t]{2}{*}{ Actin, alpha skeletal muscle } & \multirow[t]{2}{*}{ ACTA1-1 } & \multirow[t]{2}{*}{ P68138 } & \multirow[t]{2}{*}{87} & \multirow[t]{2}{*}{12} & \multirow[t]{2}{*}{5} & $5.23 /$ & $42.4 /$ & & ACTA1 \\
\hline & & & & & & & 4.71 & 33.0 & 䔅 $\begin{array}{r}1000 \\
500\end{array}$ & $\begin{array}{c}\text { a } \\
\text { 四 }\end{array}$ \\
\hline \multirow[t]{2}{*}{19} & \multirow[t]{2}{*}{ Ankyrin-2 } & \multirow[t]{2}{*}{ ANK2 } & \multirow[t]{2}{*}{ G3N0C1 } & \multirow[t]{2}{*}{64} & \multirow[t]{2}{*}{9} & \multirow[t]{2}{*}{27} & $8.15 /$ & $25.8 /$ & \multicolumn{2}{|c|}{ Uncharacterized $\mathrm{r}$} \\
\hline & & & & & & & 5.51 & 31.5 & \multicolumn{2}{|c|}{ 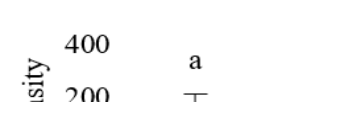 } \\
\hline \multirow[t]{2}{*}{21} & \multirow[t]{2}{*}{ 14-3-3 protein epsilon } & \multirow[t]{2}{*}{ YWHAE } & \multirow[t]{2}{*}{ P62261 } & \multirow[t]{2}{*}{63} & \multirow[t]{2}{*}{10} & \multirow[t]{2}{*}{3} & $4.63 /$ & $29.3 /$ & \multirow{2}{*}{\multicolumn{2}{|c|}{ 䂞 $\begin{array}{r}1000 \\
500\end{array}$}} \\
\hline & & & & & & & 4.25 & 27.5 & & \\
\hline \multirow[t]{2}{*}{22} & \multirow[t]{2}{*}{ Cyclin-G1 } & \multirow[t]{2}{*}{ CCNG1 } & \multirow[t]{2}{*}{ Q5E9I1 } & \multirow[t]{2}{*}{61} & \multirow[t]{2}{*}{13} & \multirow[t]{2}{*}{8} & $9.21 /$ & $34.6 /$ & & $\mathrm{CCN}$ \\
\hline & & & & & & & 4.95 & 27.1 & 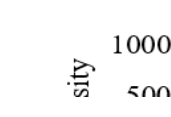 & $\frac{\mathrm{a}}{\mathrm{T}}$ \\
\hline
\end{tabular}


alkali, muscle and non-muscle

27 Transmembrane protein 233

TMEM223

A5PJW2

61

28

6

29

\begin{abstract}
Myosin regulatory light chain 2, MYLPF
\end{abstract}
Q0P571

150

47

8

skeletal muscle isoform

Myosin regulatory light chain 2, MYLPF-1

Q0P571

138

35

6

skeletal muscle isoform.

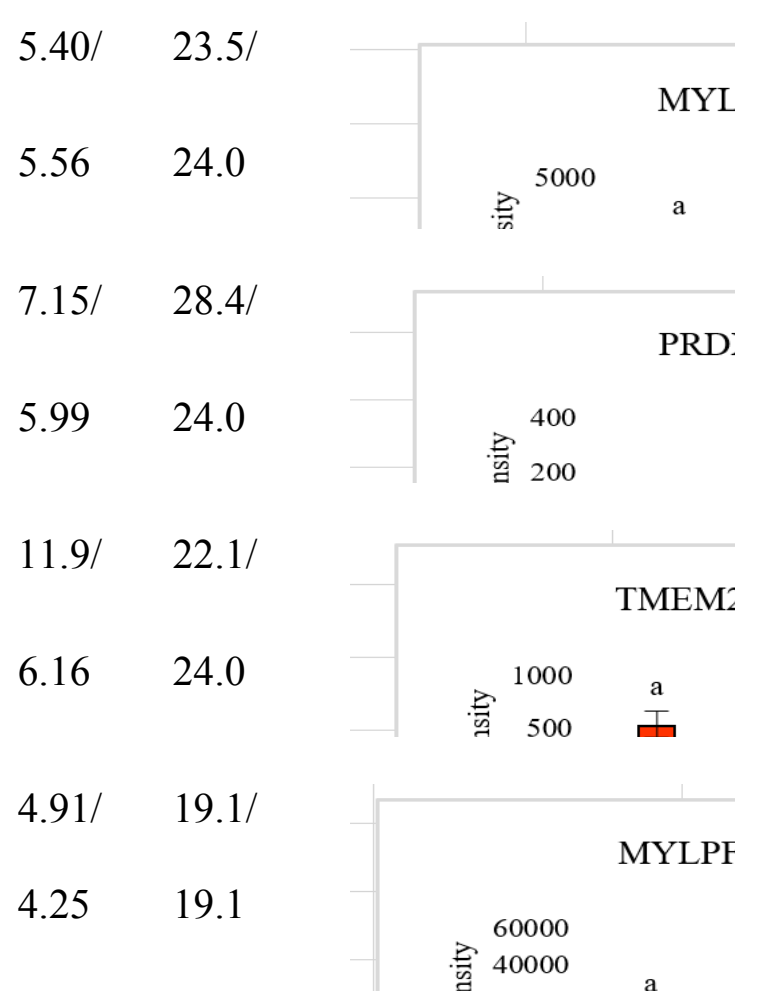

$\begin{array}{ll}4.91 / & 19.1 / \\ 4.56 & 19.1\end{array}$ 


\begin{tabular}{|c|c|c|c|c|c|c|c|c|c|c|}
\hline \multirow[t]{2}{*}{31} & Myosin regulatory light chain 2 , & MYLPF-2 & Q0P571 & 140 & 48 & 8 & $4.91 /$ & $19.1 /$ & & MYLPF \\
\hline & skeletal muscle isoform & & & & & & 4.56 & 19.1 & $\begin{array}{l}40000 \\
20000\end{array}$ & ${ }^{\mathrm{a}}$ \\
\hline \multirow[t]{2}{*}{32} & Protein FAM110A & FAM110A & Q58DG5 & 51 & 21 & 9 & $10.14 /$ & 31.8/ & & FAM1 10 \\
\hline & & & & & & & 5.02 & 16.3 & $\begin{array}{c}1500 \\
1000 \\
\cdots\end{array}$ & $\stackrel{\text { a }}{\text { 画 }}$ \\
\hline \multirow[t]{2}{*}{33} & & DUSP11 & Q5E999 & 53 & 35 & 9 & $9.32 /$ & 39.4/ & & DUSP1 \\
\hline & phosphatase & & & & & & 5.94 & 14.5 & $\begin{array}{r}1000 \\
500\end{array}$ & $\stackrel{\mathrm{a}}{\boxplus}$ \\
\hline \multirow[t]{2}{*}{34} & Protein FAM110A & FAM110A-1 & Q58DG5 & 52 & 24 & 9 & $10.14 /$ & 31.8/ & & FAM110 \\
\hline & & & & & & & 5.19 & 12.0 & 疍 4000 & $\begin{array}{l}\mathrm{a} \\
+\end{array}$ \\
\hline \multirow[t]{2}{*}{35} & Ataxin-10 & ATXN10 & Q2TBW0 & 54 & 14 & 8 & $5.08 /$ & $53.7 /$ & & ATXN11 \\
\hline & & & & & & & 5.61 & 11.7 & ${ }_{5}^{1000}$ & $\begin{array}{l}\mathrm{a} \\
-\end{array}$ \\
\hline
\end{tabular}




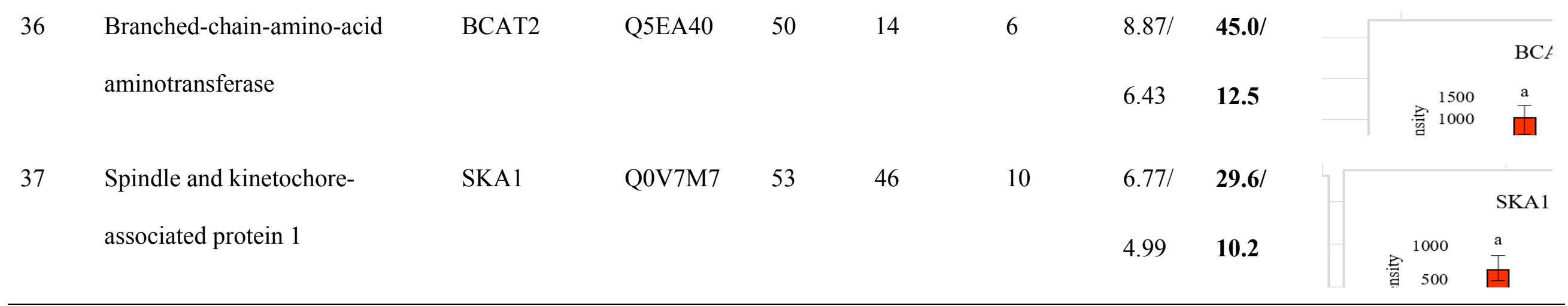

\section{${ }^{\text {a }}$ Spot position is shown in Fig 1.}

${ }^{\mathrm{b}}$ Protein identifications matched to B. taurus protein databases.

${ }^{c}$ Theoretical (Th) $\mathrm{p} I$ and $M_{\mathrm{r}}$ values were obtained from UniProtKB/Swiss-Prot databases. Protein fragments $\left[M_{\mathrm{r}}(\mathrm{Th}) / M_{\mathrm{r}}(\mathrm{Obs})>1.5\right]$ are denoted in bold.

${ }^{\mathrm{d}}$ Mean volumes obtained from six biological replicates of each bovine breed together with their 95\% CIs adjusted with the Bonferroni correction. Different lower-case letters indicate a significant difference $(P<0.05)$ in mean volume between bovine breeds. 

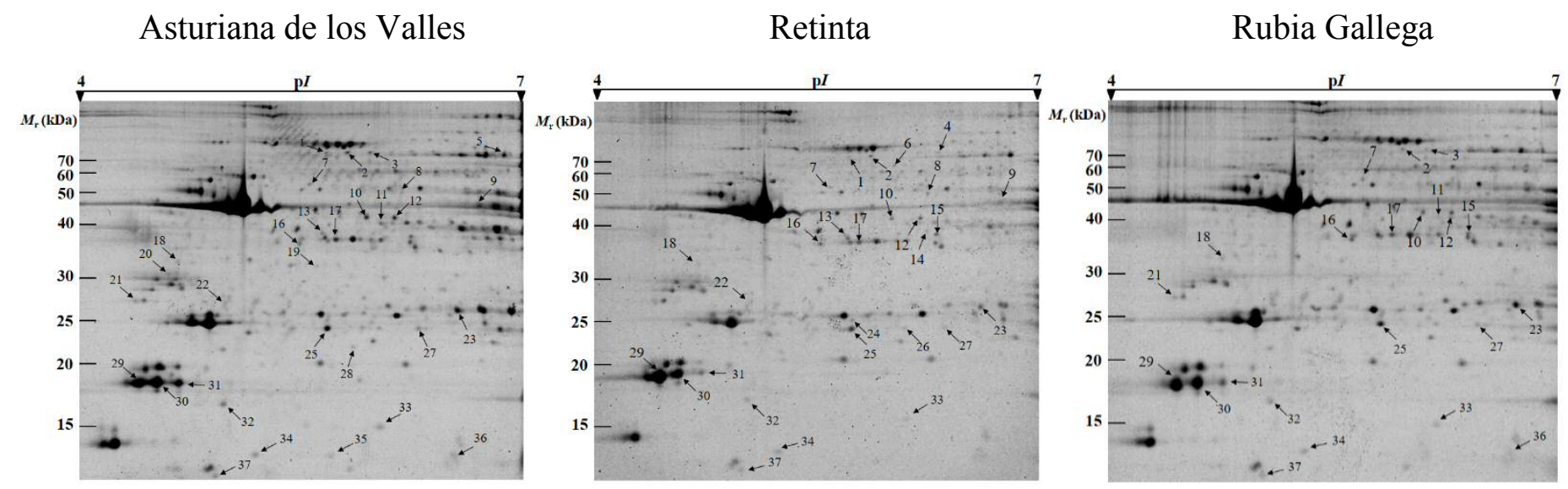

Fig. 1 


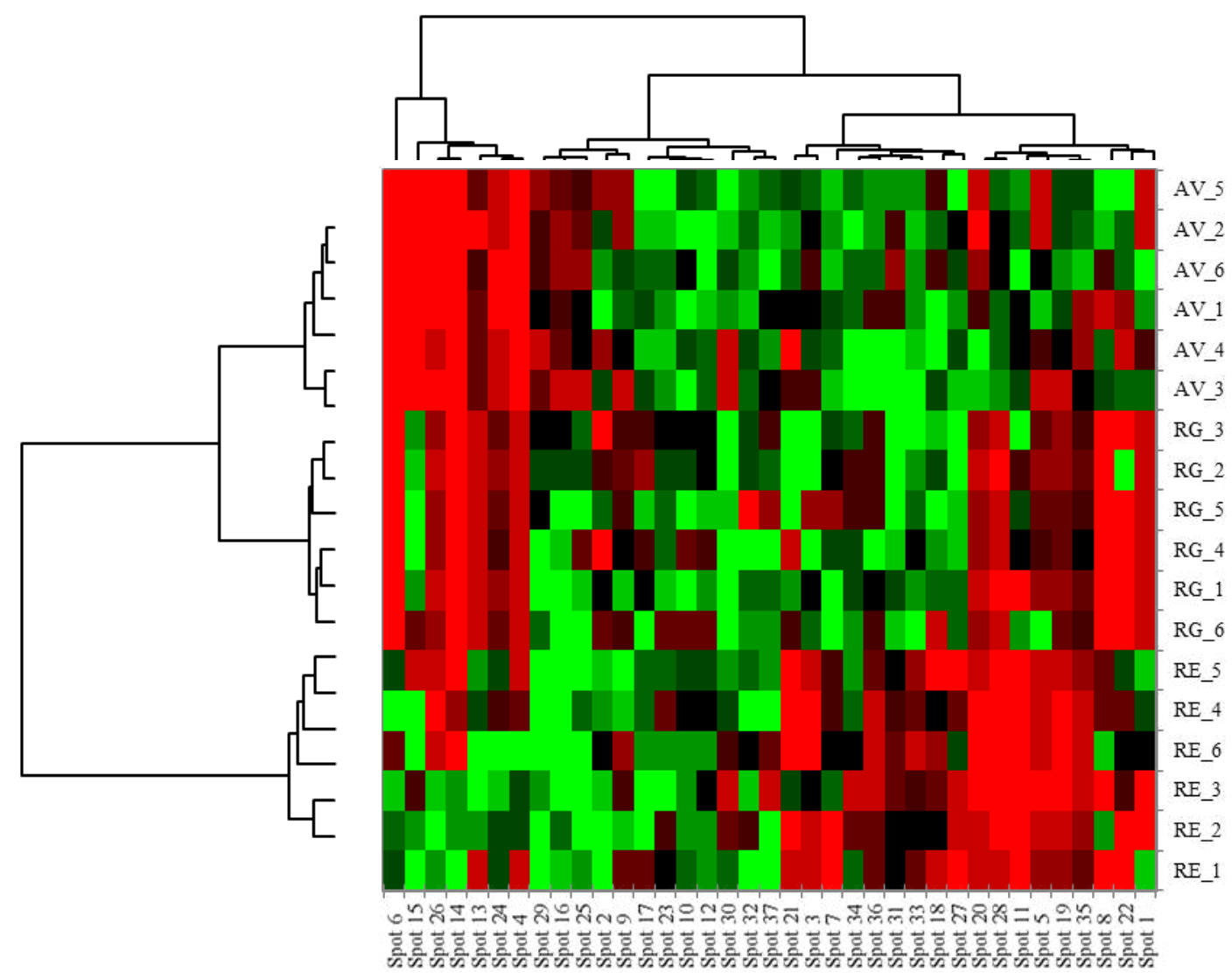

Fig. 2 
A)

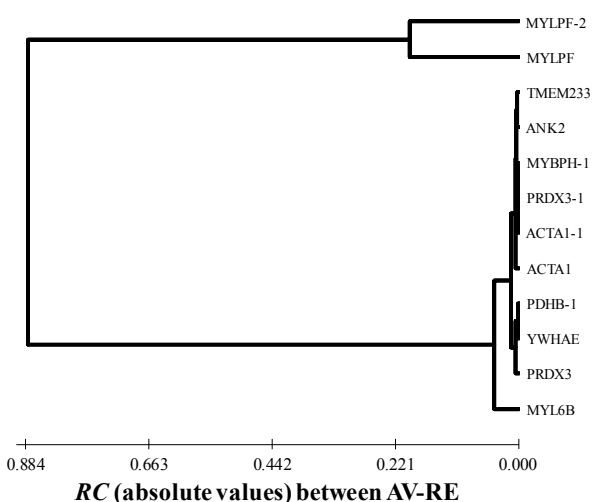

B)

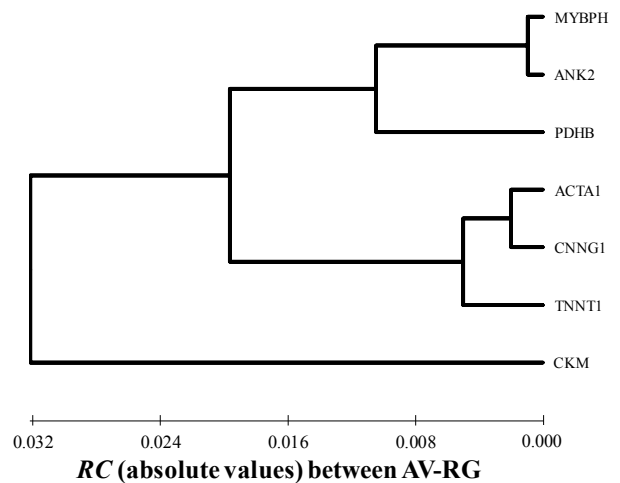

C)

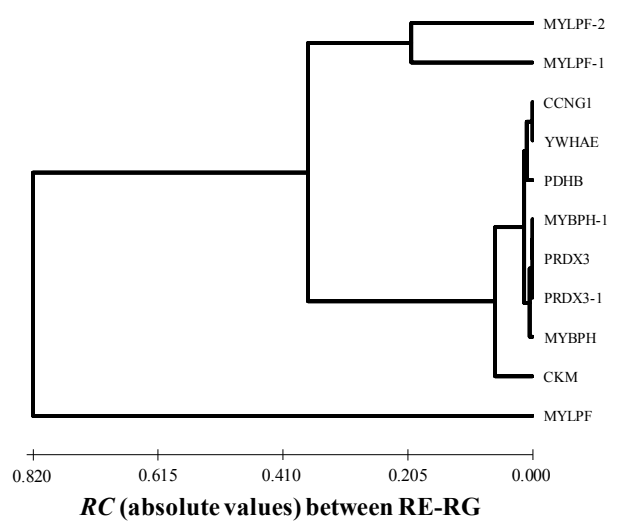

Fig. 3 


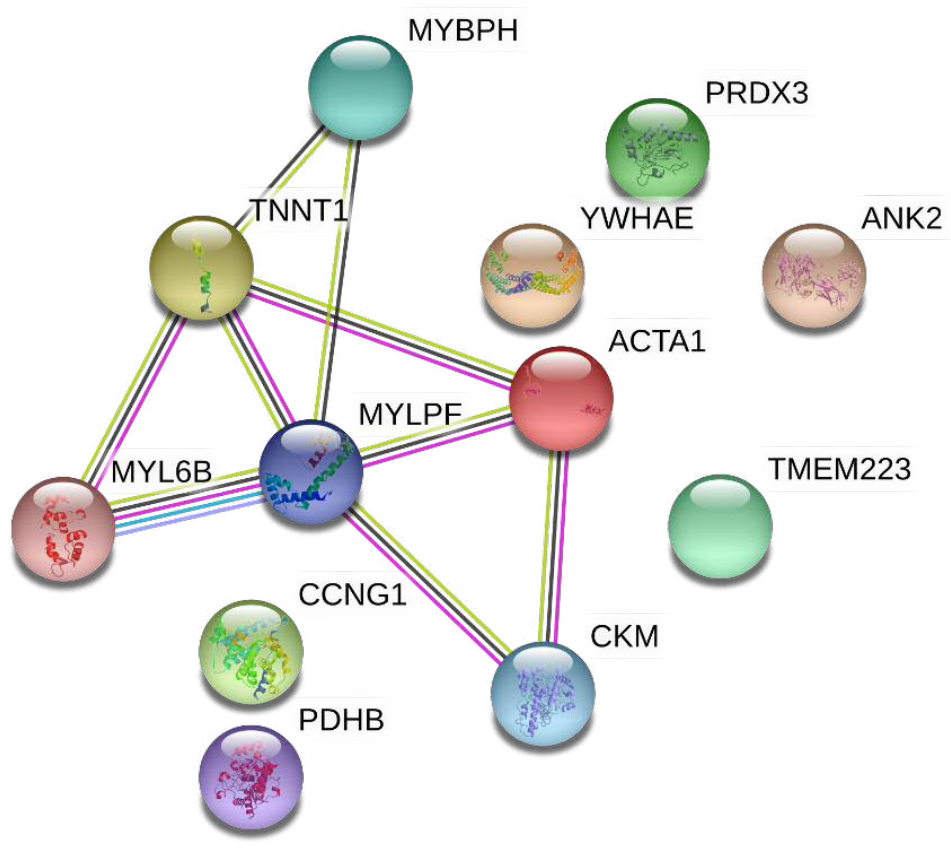

Fig. 4 

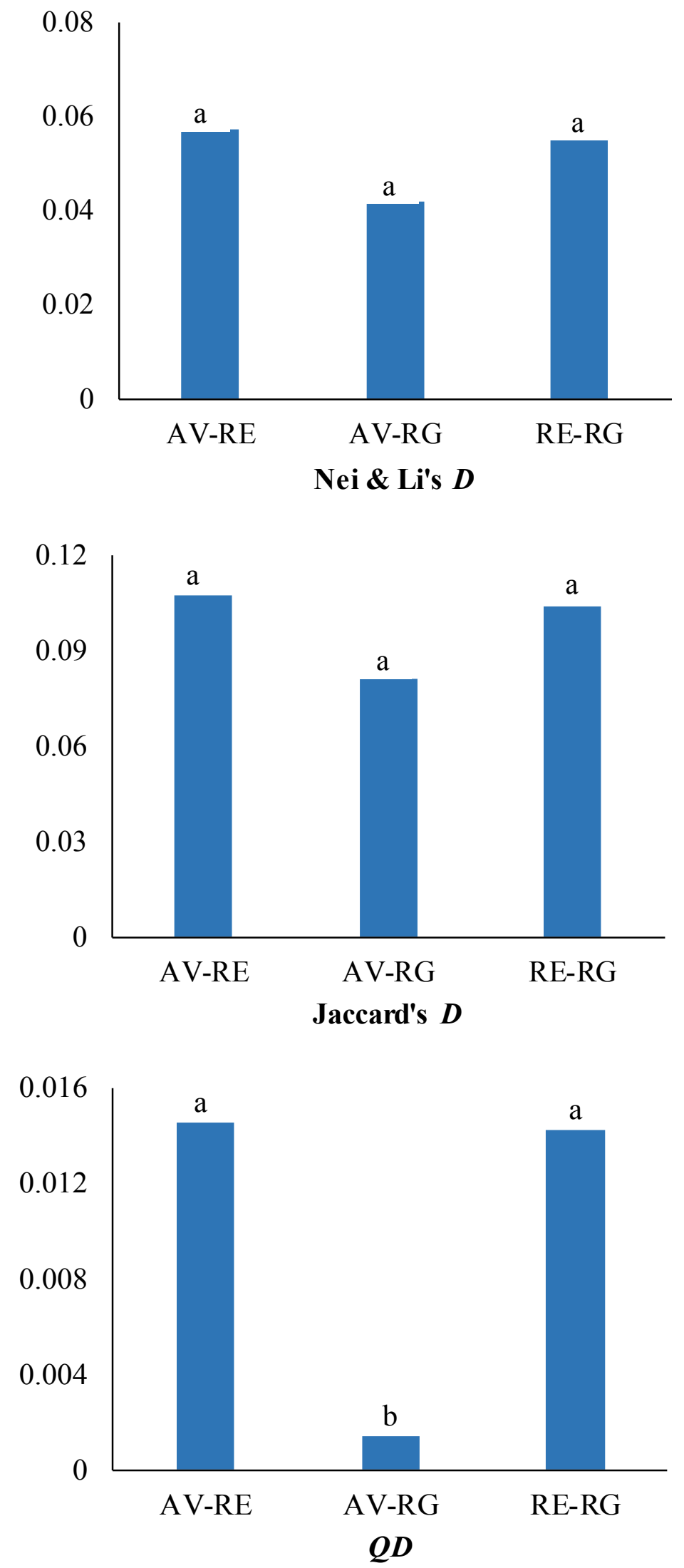

Fig. 5 


\section{Highlights}

- First assessment of quantitative proteomic distance between populations

- Novel measure $(Q D)$ for measuring quantitative proteomic distance

- Estimates of quantitative proteomic distance between Spanish beef breeds

- Protein markers of beef tenderness in Spanish breeds

- Authenticity protein markers of Spanish beef breeds 